\title{
International Joint Projects as a tool for Raising Competitive Capacity of Russian Universities: Obstacles and Means for Overcoming. Insight on Regional Implementation Practice
}

\author{
Anastasia V. Petukhovaa \\ Evgenia V. Kalininab \\ Alla A. Bylinskayaa \\ aLobachevsky State University of Nizhni Novgorod. Gagarin Avenue, 23, Nizhni Novgorod, 603950, Russia \\ Emai: alla_bylinskaya@mail.ru \\ bLobachevsky State University of Nizhni Novgorod. Gagarin Avenue, 23, Nizhni Novgorod, 603950, Russia
}

\section{Doi:10.5901/ajis.2015.v4n3s1p134}

\section{Abstract}

Apparently, there is no well-defined positive answer to the question whether education in Russian Federation is generally accessible. Specifically, for the education being available to all, it should be open to general use not only for Russian citizens, but for foreigners as well. This problem's persistence requires solving of a number of issues and overcoming numerous obstacles, related to launching and implementation of international joint projects. Undeniably, international academic programs worth making efforts and time investing. Experience of involvement of Russian universities in programs of European and international cooperation improves the quality of education.

Keywords: Competitive capacity, regional implementation practice, international joint projects, awarding joint degrees, international universities' partnership, international educational cooperation

\section{Main Text}

European Erasmus Program allows, starting from years 1980th, reckoning the periods of study of European students in partner-university (ECTS: European Credit Transfer and Accumulation System) in the framework of student mobility. The Bologna Process from 1999 (Russian Federation joined it in 2003) evokes a certain strengthening of tendencies for development of the system of academic levels (Bachelor-Master-PhD), including Tempus Projects' experience, being aimed on elaboration of equitable and comparable programs and diplomas.

Educational Act of Russian Federation (2003) allows Russian Universities to participate in different international joint projects, establish communication with foreign partner universities, and introduce into practice new methods of both educational and administration process.

According to Federal State Budget Institution "National Authorized Agency in Education Field" report, nowadays in Russia about $2 \%$ of joint diplomas projects are being realized (among the general number of all the existing projects). Joint diplomas projects of Bachelor and Master's level constitute only about 23\% from the amount of international cooperation programs in the Tempus framework.

Joint project, resulting in joint diplomas providing, supposes:

- harmonization by the partners of all the necessary aspects (study results, teaching methods, quality ensuring including evaluation ECTS, accommodation conditions and requirements for a certain level of applicants and teaching staff as well);

- acknowledgement of mobility included a partner-institution;

- carrying out of common/ mutual management;

- awarding of diploma/degree recognized by all the partners

International joint projects in general contribute to Raising Competitive Capacity of Russian Universities on educational services market. Adapting of curriculums (plans of study) of Russian and European Universities will be a meaningful step resulting in awarding joint degrees acknowledged on European educational market, being one of the necessary requirements of the Bologna Process. Such is indeed the case of functioning of namely joint international 
educational projects.

UNN (ex-NNSU) is one of the most active Russian participants of Tempus Programs supporting by European Commission (starting from 1994 NNSU carried out 18 projects). Nizhny Novgorod State University participates long term in a number of joint international educational projects with foreign universities:

- "Russian-Italian University" (in partnership with the University of Calabria, Italy);

- "Russian-French University" and joint diploma project on economics and management (in partnership with the Pierre Mendes France University, France);

- Joint Degree Project on physics with the University of Palermo.

In order to bring the quality of academic programs in NNSU to conformity with progressive international standards and to support further integration of NNSU in international educational area, the University should extend the number of joint diploma projects in cooperation with leading educational institutions ranking top-level in international rating. In particular, the University administration intends on elaboration of such projects jointly with the University of Maryland (USA), Purdue University (USA), the University of Maastricht (Netherlands), the University of Uppsala (Sweden) - topranking international institutions that have become already the partners of UNN in various international projects1.

During the period following the entering of Russian Federation into the Bologna Process, a quantity of optimistic articles and laudatory reports made appearance. Although indicating some feasible and discovered obstacles, the authors assert the possibility of overcoming them. The majority of suggestions seem to be reasonable and deliberate. However, at the same time, some difficulties mentioned just cursorily need more considerate revising. Indeed, several problems, taking into account more than 10-years long experience of international cooperation, proved to be almost insuperable, insoluble by any university itself, as exceeding the competence of a university authority.

While analyzing further activities of the international universities' partnership we should forecast all kinds of troubles in realization of a joint project and classify them between the following categories.

- Solvable problems:

- those that could be solved by the existing means and managing technologies,

- potentially solvable;

- Obstacles, that cannot be surmounted by the universities and require attention of State authorities and institutions authorized to monitor international educational cooperation:

- terminological issues,

- legal problems,

- inconsistency between existing academic standards (national standards versus international standards).

\section{Solvable Problems}

The problem of enrollment of foreign applicants for master's level in a Russian university entails the following questions: what kind of exams should the applicants pass what criteria of evaluation we should use in order to ascertain whether the foreign student is capable to meet all the necessary requirements. Thus the partner universities a supposed to jointly draw up a exacting system of criteria and requirements for the level of knowledge, skills and attainments providing the guarantee of acceptance.

The topic of financial support is ever persistent. The university authorities are compelled to decide whether the foreign master's student will pay for their studies or those will be free. And what will be the source of financial support for the joint project itself. Previously, Russian educational institutions used to obtain the opportunity of implementation of that kind of projects at the expense of funds extracting in the framework of Tempus projects and a certain number of inputs resulted in a rather successful cooperation, for example, the above-mentioned Russian-French University, realized by UNN (ex-NNSU) in partnership with the Pierre Mendes France University (Grenoble, France).

Lack of infrastructure development. First of all, it is an accommodation issue. A number of Russian universities suffer from lack of room in dormitories. Certain university authorities solve the problem at the expense of Russian students, retaining the majority of rooms (or better-equipped ones) for the benefit of foreign students.

Another important question is one of the library resources availability. International students are interested in obtaining access to the foreign publications and use of working areas in reading rooms of a university library. 
Furthermore, campus should contain gym and pool available for students and any facilities for summer activities as well.

Traditional quantity of students in a group is larger than it used to be in European universities. In order to provide more efficient interaction between student and academic instructor, university authorities should envisage dividing students in less numerous working groups.

One more organizational issue consists on educational process. L.A. Bokov phrased the difference in approach utilized in Russian and foreign institutions: we used to take into account auditoria hours whereas European practice consider the educational results. Our educational standards of 3-d generation mention them, though we have not yet elaborate any efficient methods of organization of students' self-instruction work similar to those existing in European universities already (Bokov L.A., 2013)

While analyzing the implementation process of joint projects we discover some specific regional issues.

A number of regions and cities in Russia were closed for international and even for interregional interaction as well. That resulted in backwardness of linguistic studies and lack of relevant level of foreign languages practice. Hence, several "provincial" universities though famous for their professorial staff cannot offer a large number of courses for international programs. This inconvenience could be undoubtedly overcome by engaging representatives of a new generation of teachers. Unfortunately, they do not possess yet neither sufficient teaching experience nor required degree. They cannot yet compete with the "old school" professors in the depth of theoretical and professional knowledge either.

Future trends for job placement of graduates are unfavorable. Until nowadays in Russian Federation there is not any integral system rendering foreign graduate students any assistance in placing in a job. A way out from such a deplorable state could be found in optimization of universities interaction with local potential employers.

Comparatively low rank of Russian regional academic institutions in the international ratings hampers the progress of Competitive Capacity on the international educational services market, being the cause of the lack of incentive for attraction of foreign students.

The above-mentioned obstacle draws attention to another vital point: the absence of a comprehensive system for monitoring of the attractiveness of Russian regional universities for foreign students and the lack of a criteria system for its evaluation. The experience of USA shows that about $70 \%$ of foreign students are concentrated in 200 from more than 4500 American universities. What are the guiding criteria for those applicants? What is defining the importance of the criteria? And what kind of activities should the authorities undertake in order to heighten the attractiveness of Russian regional universities? The problem requires an appropriate market research.

The problem of informational propagation is worth being mentioned. Russian academic institutions should include into inventory all the available resources in order to widespread information about advantages and benefits of courses they offer in the framework of international programs. Nowadays we face the problem of lack of information abroad about Russian regional universities.

In 2013-2014 the Research Center of International Higher Education in Boston College carried out a large-scale research project aiming to collect information about scientific centers and academic programs in the field of higher education existing in the world (Laura E. Rumbley, 2014). During the project implementation, a list of 280 journals and publications, dedicated essentially to higher education, has been composed. Analysis of the list allows emphasize fundamental tendencies of higher educational research and lines of further development of the field, necessary for open propagation of information about this area of knowledge

Insufficiency or lack of creative and business contacts between Russian regional and international academic institutions neither on the administrative level nor amongst professorial and teaching staff.

Deficient application of interactive and remote technologies in academic process hampers the progress of training.

High-scale expenses on integrated long-term mobility hinder the way of extension of quantity of students and teachers involved.

Lack of any consistent mechanism for elaboration and implementation of academic programs and deficiency of consolidated database of existing joint academic projects decelerate the process of integration of Russian universities in the worldwide academic area.

\section{Obstacles, that Cannot be Surmounted by the Universities and Require Attention of State Authorities and Institutions Authorized to Monitor International Educational Cooperation}

Terminological and semantic difficulties. The content of the "joint diploma" notion presents another complication. The wording is undoubtedly inviting, especially for any report or advertising. The question is whether it is an utopia or a feasible idea. The latest researches that frequently mention it imply joint degree in the first place. However, speaking 
about joint diploma literally we should clarify the academic level. The discrepancy of academic curriculums and difference of Student Workload on a Bachelor level between national and international academic standards keep Russian universities aside. In fact, the graduate Bachelor student awarded with the diploma of his basic university may obtain from a foreign partner-university only a certificate of training on a certain number of courses. Russian academic institutions though accumulate a similar experience in the framework of national cooperation. For example, Nizhny Novgorod Lobachevski State University and Nizhny Novgorod Dobroliubov University of Foreign Languages interact long term on a joint program of Russian-French University. However, such a pretentious title does not mean any kind of active international cooperation, as long as the teaching staff of both universities on their own, with quite a modest input of foreign partners, implement the academic process. On the other hand, this very program supply to UNN (ex-NNSU) a whole cohort of young specialists in economics and law with a high level of knowledge of English and French, sufficient for elaboration academic courses in these languages.

In general, national conceptual framework should be compatible with international one. The participants of the joint programs are supposed as well to be aware of mutual opportunities and responsibilities.

Legal issues. We have not solved yet legal issues including the problem of ensuring the quality of training. The efficient inculcation of an international program requires a normative base regulating the implementation joint diploma projects and other forms of joint academic programs (defining the status of joint programs and joint diploma projects, ECTS, system for quality assurance including study results assessment, acknowledgment of study results and diploma).

Discrepancy between existing academic standards (national standards versus international standards).

Optimistic reports on academic cooperation research display the commitment of Russian universities in implementation of joint projects (especially joint diploma/degree programs). Those surveys contain impressive statistics of joint programs propagation embracing the field of economics, engineering and natural sciences. Farther the report composers modestly specify that the majority of joint diploma projects merely cover Master and Doctorate's levels. The Bachelor's level cause does not seem so optimistic. The reason is clear: the federal state standard for Bachelor's training does not allow any space for "maneuverings" for unification of educational programs and making on academic services market any offers, which may attract foreign applicants to study in Russia. The exception is provided by specialties offering universal knowledge without any regional limitations (ex.g. technological area and natural sciences). Unfortunately, humanities do not possess that kind of autonomy. According to national standards, the quantity of training auditorial hours allotted to study national law or national economics far exceeds the quantity of hours covering international practice.

Rigid national rules defining diploma's features did not allow supplement it with any information about participation in joint programs. However new Federal Law "About Education in Russian Federation" \#273 from the 29th of December 2012 empowers academic institutions to award graduate documents of an appropriate form (art.60 p.3) to those ones that successfully got through end-of course assessment. Academic institutions themselves establish henceforth the form of graduate documents and the form of qualification certificate. The implementation of the new Federal Law "About Education" intensify tendencies for joint academic programs propagation in a network form.

\section{References}

Bokov L.A. Problems of accordance state educational standards during realization of the programs of double diplomas// International journal of experimental education №1, 2013, p. 20-21

Laura E. Rumbley, Philip G. Altbach, David A. Stan eld, Yukiko Shimmi, Ariane de Gayardon, Roy Y. Chan/. Higher Education: A Worldwide Inventory of Research Centers, Academic Programs, and Journals and Publications (3rd Edition). pp. 322 